\title{
Micrometer-scale cavities in fibrous and cloudy diamonds - a glance into diamond dissolution events
}

\author{
Ofra Klein-BenDavid ${ }^{1}$, Richard Wirth ${ }^{2}$ and Oded Navon $^{3}$
}

\author{
${ }^{1}$ Department of Earth Sciences, Durham University, Science Labs, Durham, UK, DH1 3LE. \\ ${ }^{2}$ GeoForschungsZentrum, Potsdam, Telegrafenberg, Div.4, D-14473, Potsdam, Germany. \\ ${ }^{3}$ Institute of Earth Sciences, The Hebrew University of Jerusalem, Jerusalem 91904, Israel.
}

\section{Introduction}

Diamond dissolution at mantle conditions is indicated by changes in diamond morphology and the formation of etch pits. Such patterns followed by additional diamond growth are commonly observed in cathodoluminescence images of many diamonds. Etched, cavity-rich zones followed by subsequent fibrous growth have also been observed in coated diamonds. Diamond dissolution depends on redox condition, temperature and composition of the dissolving fluid/melt and especially on the $\mathrm{H}_{2} \mathrm{O}$ content of the system. Kimberlite magmas are considered as the main corroding medium (Robinson et al., 1989), but Fedortchouk et al. (2007) demonstrated the importance of a free fluid phase (hydrous or $\mathrm{CO}_{2}$-rich), even in kimberlitic systems.

Fibrous diamonds precipitate from high-density fluids (HDF), which vary in composition between carbonatitic and hydrous-silicic end-members, or between carbonatitic and saline end members. The fibrous diamonds grow under high carbonsupersaturation conditions that accelerate growth and produce diamonds with high $\mathrm{N}$ abundance, fibril structure and numerous sub-micrometer inclusions. Nitrogen typically resides in a-centers (low aggregation state) suggesting short mantle residence time. Pressure and temperature estimates for microinclusion-bearing diamonds are similar to those of diamonds without inclusions or slightly lower.

We report the internal structure and mineralogy of cavities in inclusion-rich zones of five fibrous, coated and cloudy diamonds (Table 1). The cavities were exposed in a polished diamond slab and do not extend to the diamond surface, suggesting that they were formed at the diamond stability field and were locked in the diamond during subsequent diamond growth.

Table 1: Mineral and fluid composition of the studied diamonds

\begin{tabular}{|c|c|c|c|c|c|}
\hline Diamond & KFF 165 & UB 5-41 & UB 3105 & ON DVK 294 & CNG 2 \\
\hline Origin & $\begin{array}{l}\text { Koffiefontein, } \\
\text { South Africa }\end{array}$ & $\begin{array}{l}\text { Yubilenaya, } \\
\text { Yakutia, Siberia }\end{array}$ & $\begin{array}{l}\text { Yubilenaya, } \\
\text { Yakutia, Siberia }\end{array}$ & Diavik, Canada & Congo placer \\
\hline Habit & Cloudy & Fibrous cube & Cloudy & Coated & Fibrous cube \\
\hline $\begin{array}{l}\text { High density } \\
\text { fluid (HDF) } \\
\text { composition } \\
\end{array}$ & Saline HDF & $\begin{array}{l}\text { Mg-poor } \\
\text { carbonatitic HDF }\end{array}$ & - & $\begin{array}{l}\text { Saline-carbonatitic } \\
\text { HDF }\end{array}$ & Silicic HDF \\
\hline $\begin{array}{l}\text { Included } \\
\text { minerals }\end{array}$ & CPX, Carbonate & S-Ni-Fe inclusions & $\begin{array}{l}\text { Mg-Fe silicate, } \\
\text { Chromite, S-Ni-Fe } \\
\text { inclusions }\end{array}$ & $\begin{array}{l}\text { Cr-diopside, } \\
\text { Chromite, Olivine }\end{array}$ & - \\
\hline Paragenesis & eclogitic & unknown & peridotitic & peridotitic & unknown \\
\hline $\begin{array}{l}\text { Cavity } \\
\text { filling }\end{array}$ & $\begin{array}{l}\text { Amorphous matrix } \\
+ \text { kappa alumina } \\
+ \text { moisoniate } 6 \mathrm{H}^{+} \\
\text {nano fluorite crystal }\end{array}$ & $\begin{array}{l}\text { Amorphous matrix } \\
+ \text { carbonate } \\
\text { crystals+ corundum } \\
\text { crystals+ nano } \\
\text { ilmenite crystal }\end{array}$ & $\begin{array}{l}\text { Amorphous matrix } \\
+ \text { carbonate } \\
\text { crystals+ corundum } \\
\text { crystals+ } \\
\text { olivine+quartz }\end{array}$ & Amorphous matrix & $\begin{array}{l}\text { Al-depleted } \\
\text { amorphous matrix }+ \\
\text { nano diamond } \\
\text { crystals }\end{array}$ \\
\hline
\end{tabular}

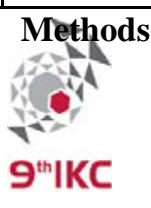


Ultra-thin diamond foils were prepared using the focused ion beam of a FIB2000 instrument at GFZ, Potsdam. TEM analysis and imaging were conducted using a Philips CM200 microscope with a LaB6 electron source and a FEI Tecnai ${ }^{\mathrm{TM}}$ G2 F20 X-Twin microscope with a FEG electron source (200 kV). Electron energy-loss spectroscopy (EELS) was conducted using a Gatan imaging filter $\left(\mathrm{GIF}^{\mathrm{TM}}\right)$. Chemical analysis was carried out using an energy dispersive X-ray spectrometer (c.f. Wirth, 2004, (Klein-BenDavid et al., 2006, 2007 for details).

\section{Results and discussion}

Cavities are found in various associations within the diamonds. They are found as isolated cavities within the diamond matrix, aligned along a healed crack or form cavity-rich layers. The cavities are anhedral in shape and their faces are commonly characterized by uneven saw-tooth structures. The material in the cavities is mostly amorphous and spongy with open pores that probably contained volatiles prior to the extraction of the foil. Crystalline phases embedded in the amorphous matrix are common (Fig 1).

Carbon is the main constituent of the amorphous matrix; nitrogen and water are present but could not be quantified. Also abundant are amorphous zones, rich in alumina silica or calcium with other elements present in smaller amounts. Such composition is distinct from that of the HDF trapped by the microinclusions.

The difference in structure and composition between the cavities and the microinclusions suggest that they represent two distinct generations. Microinclusions formed during growth while cavities formed during dissolution. Dissolution may explain the high abundance of carbon and nitrogen in the amorphous zones. The enrichment of the amorphous matrix in volatiles and in many minor elements (K, Fe, $\mathrm{Ba}, \mathrm{Mg}$, $\mathrm{Cl}, \mathrm{P}, \mathrm{Ti}$ and S) cannot be explained by the dissolution of micro-inclusions. Not only the compositions are different, but the amount of fluid in the few microinclusions that may have resided in the volume

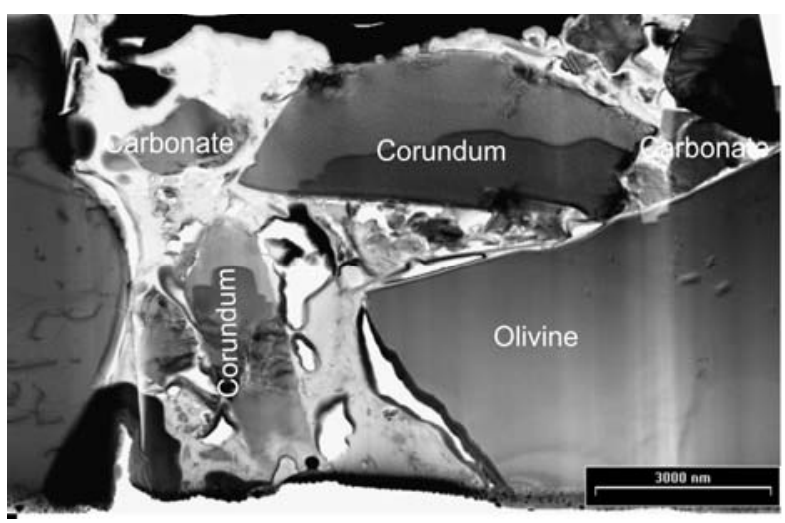

Figure 1: cavity in diamond UB 3105

that now forms a cavity is trivial. A different fluid phase must have been present during the sealing of the cavities.

Micrometer-scale crystals were observed in four of the cavities including Al-oxide (corundum and $\kappa$-alumina), Ca- and Ca-Mg-carbonates, quartz, olivine and 6Hmoissanite (e.g. Fig 1). Most crystals have anhedral shapes and show resorption features. Al-oxides, quartz and carbonate are close in composition to the Al-, Sior Ca-rich amorphous matrix. They may be related by amorphization of the former or crystallization of the latter.

We propose that dissolution proceeded from the diamond surface along cracks, fiber interfaces, or other lattice imperfections and produced surface pits and internal cavities. The pits and holes trapped some of the material dissolved from the diamond along with mineral phases and the dissolving fluid. All were later sealed by continued diamond growth.

The presence of both $\kappa$-alumina and moissanite in diamond KFF-165 (Fig 2) is difficult to explain. Under mantle conditions moissanite occurs only at highly reducing environments and $\kappa$-alumina is a metastable phase that has never been reported in nature. It is possible that diamond growth was initiated by penetration of oxidizing fluids into a reducing microenvironment which led to reduction of the fluid, to fast diamond formation and to entrapment of the microinclusions. When this fluid was consumed, reduced conditions returned, leading to partial dissolution of imperfections in the diamond and to cavity formation. 


\section{The composition of the cavity filling}

All the analyzed cavities with the exception of one are rich in alumina, silica and Ca-carbonate with alumina/silica > 1. Enrichment in silica, alumina, calcium and sodium was noted in hydrous fluids in equilibrium with eclogites at $4-7 \mathrm{GPa}$ and $700-1400^{\circ} \mathrm{C}$ (Kessel et al., 2005). At 5 GPa, near solidus fluids and melts are rich in silica and alumina, which together make $\sim 80 \%$ of the solute. The solute content increases sharply upon heating from 900 to $1300^{\circ} \mathrm{C}$ and the $\mathrm{Al}_{2} \mathrm{O}_{3} / \mathrm{SiO}_{2}$ ratio of the fluid/melt increases. Observation by Manning (2006) also support increasing solubility of alumina with pressure and temperature in the $\mathrm{SiO}_{2}-\mathrm{Al}_{2} \mathrm{O}_{3}-\mathrm{Na}_{2} \mathrm{O}-\mathrm{Cl}$ system.

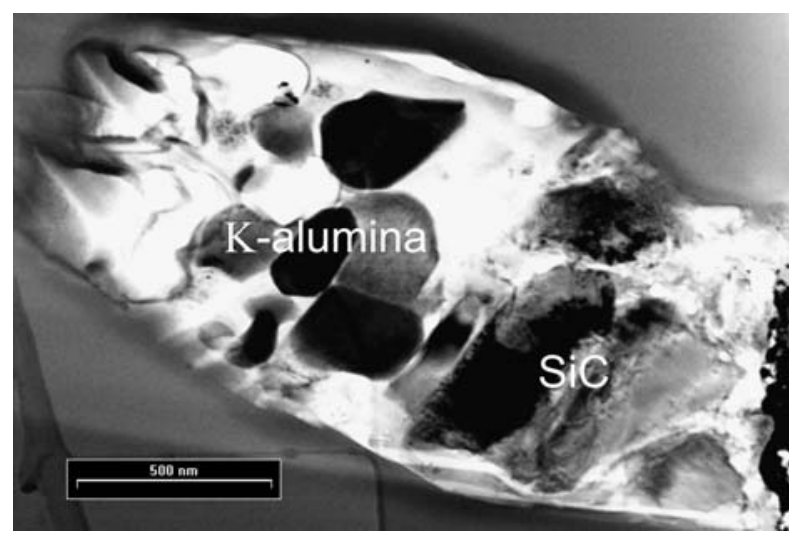

Figure 2: cavity in diamond KFF 165

As temperature rises towards the solidus the solute content of the fluids increases rapidly, while water content remains relatively constant at $\sim 20 \%$. Thus, we expect that cooling would lead to deposition of the excess solute. While silica dominates the solute, the decrease in the $\mathrm{Al}_{2} \mathrm{O}_{3} / \mathrm{SiO}_{2}$ ratio upon cooling should lead to preferential precipitation of the alumina.

Diamond dissolution leads to the formation of $\mathrm{CO}_{2}$ or carbonate. The solubility of both silica and alumina decreases in the fluid/melt as it grows more carbonatitic. Thus, the interaction of hydrous fluids or near-solidus melts with diamonds may lead to diamond dissolution, carbonation of the fluid/melt and precipitation of non-carbonatitic components such as alumina and silica. Trapping of such fluids/melts together with excess alumina may explain the chemical composition of the cavity fillings.
The composition of hydrous fluids in equilibrium with peridotite is not well known, but alumina enrichment has been documented at grain boundaries in mantle xenoliths. Selective dissolution of grain edges during infiltration of volatile rich fluids/melts through mantle rocks would enrich the fluid in elements that strongly partition to grain boundaries Hiraga et al. (2004).

Diamond precipitation is governed by the presence of carbonate-rich diamond-forming HDFs that are trapped in the microinclusions, whereas cavity formation occurs in the presence of fluids that are less common in the diamond source region. The diamond forming HDFs are related to carbonate enrichment in the mantle and may have a genetic relationship to kimberlitic melts, whereas the cavities represent less common events where corrosive fluids are introduced and lead to diamond dissolution.

\section{References}

Fedortchouk Y., Canil D., and Semenets E. (2007) Mechanisms of diamond oxidation and their bearing on the fluid composition in kimberlite magmas. American Mineralogist 92, 1200-1212.

Hiraga T., Anderson I.M. and Kohlstedt D.L. (2004) Grain boundaries as reservoirs of incompatible elements in the Earth's mantle, Nature 427, 699-703.

Kessel R., Ulmer P., Pettke T., Schmidt M. W., and Thompson A. B. (2005) The water-basalt system at 4 to $6 \mathrm{GPa}$ : Phase relations and second critical endpoint in a K-free eclogite at 700 to 1400 degrees C. Earth and Planetary Science Letters 237(3-4), 873-892.

Klein-BenDavid O., Wirth R., and Navon O. (2006) TEM imaging and analysis of microinclusions in diamonds: a close look at diamond-growing fluids. American mineralogist 91, 353-365.

Klein-BenDavid O., Wirth R., and Navon O. (2007) Micrometer-scale cavities in fibrous and cloudy diamonds - A glance into diamond dissolution events. Earth and Planetary Science Letters 264(12), 89-103.

Manning C. E. (2006) Mobilizing aluminum in crustal and mantle fluids. Journal of Geochemical Exploration 89(1-3), 251-253.

Robinson D. N., Scott J. A., Niekerk A. V., and Anderson V. G. (1989) The sequence of events reflected in the diamonds of some southern African kimberlites. Kimberlite and Related Rocks, 990-100.

Wirth R. (2004) Focused Ion Beam (FIB): A novel technology for advanced application of micro- and nanoanalysis in geosciences and applied mineralogy. European Journal Of Mineralogy 16(6), 863-876. 